\title{
The Effects of Fasting on Toluene Metabolite (Hippuric Acid) Excretion in Urine (A Case Study of Shoe-Makers in Tambak Oso Wilangun Village-Surabaya)
}

\author{
Erwin Dyah Nawawinetu', Abdul Rohim Tualeka² \\ ${ }^{1}$ Health Department, Vocational Faculty, Airlangga University, ${ }^{2}$ De partment of Occupational Health and Safety, \\ School of Public Health, Airlangga University, Indonesia
}

\begin{abstract}
Background: An increase in toluene metabolite (hippuric acid) excretion in urine can be stimulated by such factors as fasting, smoking and coffee consumption. This research aimed at studying the effects of fasting on urinary toluene excretion of shoemakers in Tambak Oso Wilangun-Surabaya.

Method : This controlled case-study was conducted to 20 workers with purposive sampling method from the population. The independent variables of the study include toluene concentration, fasting or not fasting condition, smoking, and coffee consumption. The dependent variable was urinary hippuric acid concentration. Pearson Correlation test was conducted to identify the correlation between toluene concentration and hippuric acid concentration. Paired-t-test was used to compare hippuric acid concentration in fasting and non-fasting condition. The correlations between coffee consumption and smoking and hippuric acid concentration were analyzed by using chi-square test $(\alpha=0,05)$. Risk assessment was used to identify the health risk from occupational toluene exposure.
\end{abstract}

Result: The research showed that most of the respondents $(65 \%)$ were at risk to health problems related to toluene exposure $(\mathrm{RQ}>1)$. The statistical tests showed no significant correlation between toluene concentration and hippuric acid concentration; there was a significant difference between hippuric acid concentration before and after fasting $(p=0,016 ; p<\alpha)$; there was a significant correlation between hippuric acid concentration (non fasting) with smoking habit ( $\mathrm{p}=0,022)$, coffee consuming habit ( $\mathrm{p}=0,025)$; and between hippuric acid concentration (in fasting condition) with coffee consuming $(p=0,039)$.

Conclusion: Fasting, coffee consuming and smoking habit can increase urinary hippuric acid excretion. It is recommended for future researcher to control both coffee consumption and smoking when investigating the effects of fasting to urinary hippuric acid excretion to avoid biased results. Respondents are suggested to improve ventilation system in their workshops and use chemical cartridge respirator, apron and gloves while working.

Keywords: fasting, hi ppuric acid concentration, toluene, smoking, coffe consumption

Corresponding author

\section{Abdul Rohim Tualeka}

Occupational Health and Safety Department, School of Public Health, Airlangga University

Kampus C, Jalan Mulyorejo, Surabaya, 60115, Indonesia, Tel: +62 31 5920948, Fax: +62 315924618

E-mail: inzut.tualeka@gmail.com

\section{Introduction}

Toluene found in shoe adhesive is a member of BTX (Benzene, Toluene, and Xilene) solvents and its toxic effects are often debated. This solvent is derived from benzene and is mostly used to replace benzene for its lower effect for health. However, the effects of occupational exposure of this solvent should still be considered because this solvent is non- polaric and 
can be accumulated in the body (adiposal tissue). Toluene accumulation may cause irreversible chronic neurological symptoms.

An effective toluene metabolism can increase toluene elimination in the form of hippuric acid, and therefore it reduces its toxicity. Several factors that influence the urinary excretion of hippuric acid include fasting and low carbohidrate and high protein diets. Tea and coffee consumptions can also increase the urinary hippuric acid concentration. Tomukin argues that the hippuric acid in urine of persons without toluene exposure is $0,44 \pm 0,2 \mathrm{gr} / \mathrm{L}$. The test is conducted immediately after the end of the shift. ${ }^{1}$ This reseach particularly aimed at investigating the effect of fasting on toluene metabolite excretion in urine of shoe makers at workshops in Tambak Oso Wilangun, Surabaya.

\section{Methods and Material}

This research used a case control approach with 20 respondents selected purposively among shoe makers in several workshops located in Kelurahan Tambak Oso Wilangun, $R W I$ and $R W I I$. The independent variables in this research were the toluene consentration found in breathing zone of the workers (during fasting and non-fasting condition), smoking habit, and coffee consuming habit. The dependent variables were the concentration of hippuric acid in urine with unit of $\mathrm{mg} /$ $\mathrm{L}^{2}$. . The correlation between toluene and hippuric acid concentration was tested using Pearson correlation test. The differences of hippuric acid in urine in fasting and non-fasting conditions were tested using paired t-test. The correlation between hippuric acid concentration in urine and smoking and coffee intake was tested using chi square $(\alpha=0,05)$. Risk assessment was conducted to identify the risk of long term occupational exposure of toluene by comparing the exposure with RfC (Refference Concentration) and calculating the RQ (Risk Quotients). Preliminary research to find the location of shoe workshops was conducted before field samplings were taken.

The risk characteristic was formulated by calculating the estimated risk level using RQ equation below:

$$
\begin{aligned}
& \text { Risk Quotients }(R Q)=\text { Intake }\left(\mathrm{m}^{3} / \mathrm{kg} \text {-day }\right) \\
& R f C / R f D\left(\mathrm{~m}^{3} / \mathrm{kg}\right. \text {-day) }
\end{aligned}
$$

If $R Q$ value is less than 1 ( $R Q \leq 1)$, this indicates that the risk is acceptable. However, any efforts should be done to keep the RQ value less than 1 . If the RQ value is more than $1(\mathrm{RQ}>1)$, this denotes that the risk is unacceptable as the exposure of the risk agent is becoming serious health hazard. In this situation, the risk control of the exposure is required ${ }^{3 .}$

The measurement of toluene concentration in breathing zone around the workshops was conducted using NIOSH 1501 method with charcoal sorbent tubes and Gas Chromatography technique ${ }^{4}$. The toluene sampling was done from $12.22-13.55$ p.m. (Western Indonesia Time). The urinary hippuric acid test was conducted using HPLC instruments with NIOSH 8301 method $^{1 \cdot}$ The measurement of hippuric acid concentration was done twice; first, when the workers were not fasting; and second, after they were fasting for consecutive three days. The urine samplings were taken at 12.00 p.m.

\section{Result and Discussion}

\section{Toluene Concentration}

The measurement of the toluene concentration found in workers's respiratory area showed that the level of toluene concentration were around 0.212 ppm and $138.882 \mathrm{ppm}\left(0.365 \mathrm{mg} / \mathrm{m}^{3}\right.$ sd $523.224 \mathrm{mg} /$ $\left.\mathrm{m}^{3}\right)$. Integrated Risk Information System proposed that the inhalation reference dose or RfC (Reference Concentration) of toluene is $5 \mathrm{mg} / \mathrm{m}^{3}(=1.43 \mathrm{mg} /$ Kgweight/day $)^{5}$. When the workers experience long term occupational exposure of toluene, the concentration of the toluene should be less than $5 \mathrm{mg} / \mathrm{m}^{3}$, so that this will not cause any neurological symptoms and disorders.

Table 1. Distribution of of toluene concentration found in breathing zone of the workers based on RfC level at shoe workshops in Tambak Oso WilangunSurabaya, 2015

\begin{tabular}{|l|l|l|}
\hline $\begin{array}{l}\text { Exposure of } \\
\text { Toluene }\end{array}$ & $\begin{array}{l}\text { Respondentsxposure of } \\
\text { Tolueneshops in Tam bak } \\
\text { Oso Wilangun-Surabaya. } \\
\text { thing zone of the workers } \\
\text { based on Rfc vating for } \\
\text { three days. }\end{array}$ & $\begin{array}{l}\text { Percentage } \\
(\%)\end{array}$ \\
\hline$>$ RfC & 13 & 65 \\
\hline$\leq$ RfC & 7 & 35 \\
\hline Total & 20 & 100 \\
\hline
\end{tabular}

Note $: \mathrm{RfC}=5 \mathrm{mg} / \mathrm{m}^{3}$ 
Table 1 shows The RQ measurement indicated that $65 \%$ of the respondents have RQ value more than 1 (RQ $>1$ ). In other words, the workers in these workshops experienced health problems as they were occupationally exposed to toluene for a long period of time.

In addition to the RfC level, RQ value can also be used to assess the risk of toluene exposure. When the RQ value is more than $1(\mathrm{RQ}>1)$, the workers will be at risk of health problems other than cancers. The RQ value is obtained by dividing the daily intake (I) with $R f c$. Workers with long term occupational exposure of toluene will mainly experience neurologic symptoms. A previous research found that about $80,88 \%$ of shoe workers in these areas experienced neurologic symptoms in the form of tingling. This research found that these symptoms were caused by polyneuropathy resulted from long term exposure of high concentrated toluene.

\section{Hippuric Acid Concentration}

Table 2 The concentration of hippuric acid in urine in fasting and non-fasting condition, Tambak Oso Wilangun Surabaya, 2015.

\begin{tabular}{|l|l|l|l|l|}
\hline \multirow{2}{*}{$\begin{array}{l}\text { Hippuric acid } \\
\text { concentration } \\
(\mathrm{g} / \mathrm{L})\end{array}$} & \multicolumn{2}{|l|}{ Non fasting } & \multicolumn{2}{l|}{ Fasting } \\
\cline { 2 - 5 } & Respondents & $\%$ & $\begin{array}{l}\text { Respon- } \\
\text { dents }\end{array}$ & $\%$ \\
\hline$<0.24$ & 3 & 15 & 2 & 10 \\
\hline $0.24-0.64$ & 11 & 55 & 12 & 60 \\
\hline$>0.64$ & 6 & 30 & 6 & 30 \\
\hline
\end{tabular}

The urinary hippuric acid concentration of ma jority of the respondents in this research was at normal range which was around $0.24-0.64 \mathrm{~g} / \mathrm{L}$. The statistical test indicated significant difference of hippuric acid concentration in fasting and non-fasting conditions $(p=0,016 ; p<\alpha ; \alpha=0,05)$.
These findings were in line with that of Hogan C Michael who did similar research of the effects of fasting on the excretion of hippuric acid. Fasting and low carbohydrate diet will increase the production of CYP2E1 (cytochrome P450) enzymes that play important roles in toluene metabolism ${ }^{6}$.

Cytochrome P450 enzymes are very essential for functional reaction of human body, particularly when exposed to poisonous chemical substance. These enzymes will metabolise the toluenes to mainly benzyl alcohol and o-cresol and p-cresol. The benzyl alcohol will then be metabolised by CYP into benzaldehide. Benzaldehide will then be metabolised into benzoate acid mainly by ALDH-2 (Aldhehyde dehydrogenase-2) from mitochondria, and some by ALDH-1 from cytosol. Benzoate acid will react through two metabolism routes. First, the route of glucoronate acid that will metabolize benzoate acid to benzoyl glucoronide will be excreted in urine (10-20\%). Second, benzoate acid will be metabolised to benzoyl Co-A by benzoyl co-A synthetase enzymes, and this will be changed into hippuric acid by benzoyl Co-A:glycine N-Acyltrenasferase enzym. Hippuric acid is the main metabolite of the toluene.

\section{Correlation Between Toluene and Hippuric Acid Concentrations}

The correlation between toluene concentration and the first hippuric acid concentration indicated that higher toluene concentration results in higher the hippuric acid concentration with values ranged between $0.24-0.64 \mathrm{~g} / \mathrm{L}$ and $>0.64 \mathrm{~g} / \mathrm{L}$. However, there was no significant correlation between toluene and hippuric acid concentrations before fasting $(p=0.9 ; p>\alpha)$, and there was also no significant correlation between toluene and hippuric acid concentration after a three-day fasting $(\mathrm{p}=0.068 ; \mathrm{p}>\alpha)$.

Table 4 The correlation between toluene concentration and first hippuric acid concentration of workers based on RfC value, Tambak Oso Wilangun- Surabaya, 2015.

\begin{tabular}{|l|l|l|l|l|l|l|}
\hline \multirow{2}{*}{ Toluene Concentration } & \multicolumn{6}{l}{ First Hipp uric Acid Concentration (mg/m3) } \\
\cline { 2 - 8 } & $<\mathbf{0 . 2 4}$ & $\%$ & $0.24-0.64$ & $\%$ & $>0.64$ & $\%$ \\
\hline$\leq$ RfC & 2 & 100 & 2 & 16.67 & 3 & 50 \\
\hline$>\operatorname{RfC}$ & 0 & 0 & 10 & 83.33 & 3 & 50 \\
\hline Total(\%) & 2 & 100 & 12 & 100 & 6 & 100 \\
\hline
\end{tabular}


Table 5 below shows the correlation between toluene concentration and hippuric acid concentration after three day fasting:

Table 5 The correlation between toluene concentration and hippuric acid concentration after fasting of workers based on RfC value, Tambak Oso Wilangun Surabaya, 2015.

\begin{tabular}{|l|l|l|l|l|l|l|}
\hline \multirow{2}{*}{$\begin{array}{l}\text { Toluene } \\
\text { concentration }\end{array}$} & \multicolumn{6}{l}{ Hippuric acid concentration after fasting (mg/m3) } \\
\cline { 2 - 8 } & $<\mathbf{0 . 2 4}$ & $\mathbf{\%}$ & $\mathbf{0 . 2 4 - 0 . 6 4}$ & $\%$ & $>\mathbf{0 . 6 4}$ & $\%$ \\
\hline$\leq$ Rfc & 0 & 0 & 3 & 33.33 & 4 & 40 \\
\hline$>$ Rfc & 0 & 0 & 6 & 66.67 & 6 & 60 \\
\hline Total (\%) & 0 & 0 & 9 & 100 & 10 & 100 \\
\hline
\end{tabular}

The metabolism of toluene exposure in human body can be excreted as urinary hippuric acid. This biomarker can be used as an indicator of toluene exposure and represent $60 \%-70 \%$ of toluene metabolism ${ }^{5,7}$.

Toluene Intake were calculated using the

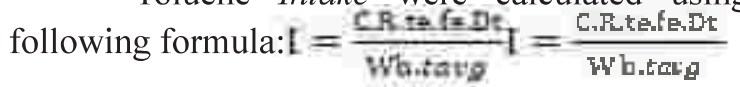

From the calculation, it was found that the $I$ (toluene intake) value was ranged between 0.09 and $92.98 \mathrm{mg} /$ weight/day. If each participant was assumed to have a normal metabolic function, $60-70 \%$ of this intake would be excreted as urinary hippuric acid.

The human body will react defensively to all poisonous substance to avoid health problems. One of the defensive mechanisms is called detoxification or biotransformation which is also known as metabolism. In this process, the body will transform fat-soluble substance into water soluble substance, so that this substance can easily be released through excretion route. Toluene is a lipofilic substance and will be fast distributed to brain, liver, and kidney.

The amount of $80 \%$ of the absorbed toluene is oxydized into benzoic acid in the liver, which is later conjugated by glycin to form hippuric acid. The benzoic acid is also conjugated by glucoronate acid to form benzoyl glucoronate. Very few portion of absorbed toluene is oxydized in aromatic ring and forms ortho and para-cresol. Most of the inhaled and ingested toluene is excreted in urine twelve hours after exposure. About $20 \%$ of the toluene is eliminated through respiratory exhalation and less than $2 \%$ of the total toluene metabolite is excreted in liver ${ }^{8}$.

Tomukin argued that the concentration of hippuric acid of persons without toluene exposure is $0.44 \pm 0.2$ gram/litre urine or ranged between 0.24 and $0,64 \mathrm{gr} / \mathrm{L}^{1}$. The study showed that the hippuric acid concentration before the treatment (fasting) was 0,08 to $1.47 \mathrm{gram} / \mathrm{L}$ urine. The study found that $35 \%$ of the respondents had hippuric acid concentration over $0.64 \mathrm{gr} / \mathrm{L}, 60 \%$ of the respondents had the concentration ranged between 0.24 and $0.64 \mathrm{gr} / \mathrm{L}$, and the rest $5 \%$ of the respondents had concentration lower than that of the normal concentration. In other words, $65 \%$ of the respondents had normal toluene concentration which was similar to those who were not exposed to toluene. This finding was in contrast with the fact the toluene concentration found in breathing zone around the workshops is higher than the accepted concentration. Pearson test was therefore conducted, and it was found that there was no significant correlation between toluene concentration in breathing zone and hippuric acid concentration before the treatment.

There were several reasons that explained the low excretion of hippuric acid among the workers in this research. First, there was an inefficient metabolism caused by improper function of metabolic organs. This reason, however, still needs to be further justified. The second reason is insufficient intake of nutrition which will be further investigated. The third reason was high carbohydrate and low protein diets. Longer elimination of the toluene increases its possibility to cause health problems. The toluene excretion was completed after 12 hours of toluene free exposure. In this research, the 
workers started working at 8 a.m. and finished at 2 am with short break for meals and other personal activities. When these workers had to come back to work at the same time in the following morning, they had only 6 hours being unexposed to toluene. This situation had made complete toluene excretion difficult or impossible and caused toluene accumulation in certain organs and adiposal tissues and increased its toxicity. The working situation in these workshops required the workers to work very long hours, and the most sensible way to reduce toluene exposure for the workers was to improve the ventilation system and to require them to wear respirators appropriately designed for toluene solvent.

The Correlation between Hippuric Acid Concentration and Smoking Habit

This research found that the respondents with smoking habit had higher concentration of hippuric acid in urine compared to those who were not smokers. The excretion of hippuric acid with concentration higher than $0.64 \mathrm{gr} / \mathrm{L}$ was found more in workers with smoking habit (45.45\%) than that in workers who were not smokers (11.11\%). The chi-square test indicated that there was a significant correlation between hippuric acid concentration and smoking $(p=0.022, p<\alpha)$.

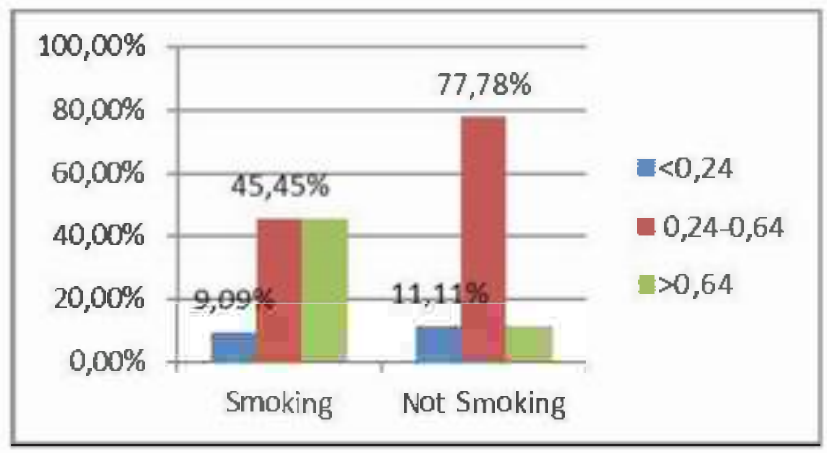

Figure 1 Hippuric acid concentration found in workers with and without smoking habits in non-fasting situation, Tambak Oso Wilangun Surabaya, 2015.

The concentration of hippuric acid $(>0.64 \mathrm{~g} / \mathrm{L})$ was four times higher in fasting than in non-fasting condition. However, the hippuric acid concentration and the smoking habits was not significantly correlated $(\mathrm{p}=0.491, \mathrm{p}>\alpha)$. This shows that fasting, and not necessarily the smoking habit, has caused higher concentration of hippuric acid excretion. There was a significant correlation between hippuric acid concentration and smoking habit in non-fasting condition. This means that, in non-fasting condition, more toluene was inhaled from the cigarette smoke.

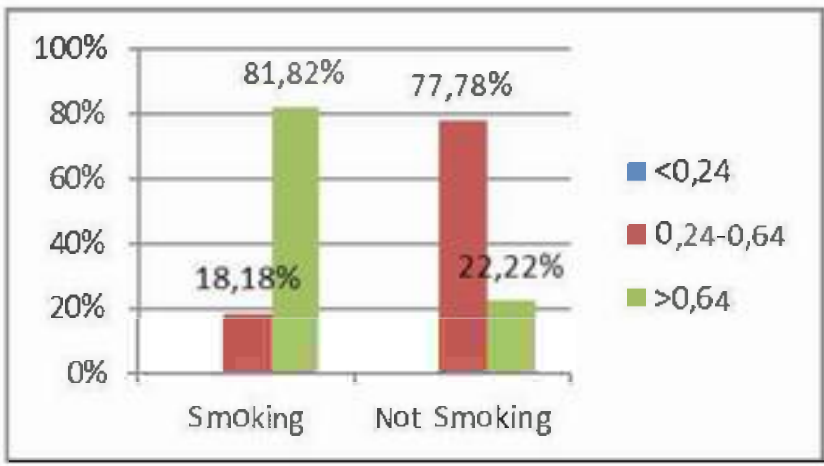

Figure 2 Hippuric acid concentration in fasting condition found in workers with and without smoking habits, Tambak Oso Wilangun-Surabaya, 2015

In this research, toluene was contributed from the solvent used both in shoe adhesives and from the cigarette smoke. It was argued that the increase of urinary hippuric acid concentration in smokers was not due to the fact that smoking could increase the hippuric acid excretion. Other research found that smoking reduced all metabolite excretion (including hippuric acid) by $30 \%$. So, it can be concluded that the increase of hippuric acid concentration in urine due to the fasting effect.

Cigarette smoke that contains toluene apparently increases the toluene concentration in the breathing zone which in turn increases the toluene intake of the workers. The increase of toluene intake will increase the induction of CYP2EI enzymes. These enzymes are essential for toluene metabolism. In other words, these enzymes are the main routes for toluene metabolism. In addition, toluene is flammable and therefore smoking should strongly be forbidden in works that involved toluene.

Theoretically, the main route of toluene metabolism is through CYP2EI enzymes, also known as cytochrome P450. Fasting increases the production of these enzymes, and therefore toluene metabolism becomes more effective. This research was conducted during the fasting month, and this helped explain the benefits of fasting for the excretion of toluene. The participants in this research were fasting for three days. With the limited fasting time involved in this study, this study could not yet determine how long the workers should do fasting to ensure a complete toluene excretion from their body. The short fasting days were also due to the fact that during the fasting month, the workers in these shoe workshops often broke fasting as they were required to work full time to meet high orders from the customers. 
Another research reported that there was a decrease of hippuric acid in urine after one month fasting. In this case, there should be a further research related to the influence of fasting on toluene metabolite (hippuric acid) excretion. Fasting, as it is not followed by proper intake of nutrition, will decrease the protein, and sufficient protein is vital in reducing the toxicity of poisonous substance. Still another research found that low protein diet has reduced the hippuric acid excretion in urine. These findings are in line with those of Michael, C. Hogan who argued that both low carbohydrate diet and fasting affect the CYP2E1 enzymes that will increase the toluene metabolism into benzoate acid. This acid is then conjugated by glycin into hippuric acid that is excreted in urine. Furthermore, the low protein diet decreases the CYP that reduces the speed of toluene elimination ${ }^{6}$.

Correlation Between Hippuric Acid Concentration and Coffee Consuming Habit

This research found that respondents with coffee consuming habit had first concentration of hippuric acid higher than $0.64 \mathrm{~g} / \mathrm{L}(33.33 \%)$ compared to that of respondents who were not coffee consumers $(0 \%)$. During fasting, the respondents with coffee consuming habit with hippuric acid concentration $>0.64 \mathrm{gr} / \mathrm{L}$ was higher $(81,82 \%)$ compared to that of respondents without coffee consuming habit. The statistical test found that there was a significant correlation between hippuric acid concentration and coffee consumption before and during fasting ( $\mathrm{p}=0.025$ and $\mathrm{p}=0.039$ ).

These findings are similar to those of Masahiro Munaka, et al, that the concentration of hippuric acid in individuals with heavy coffee consumption is significantly higher than that of individuals who are not coffee consumers ${ }^{10}$. Heavy coffee consumers are defined as individuals who consume more than two cups of coffee per day. All respondents in this study were categorized as heavy consumers as they in average consumed two or more cups of coffee a day.

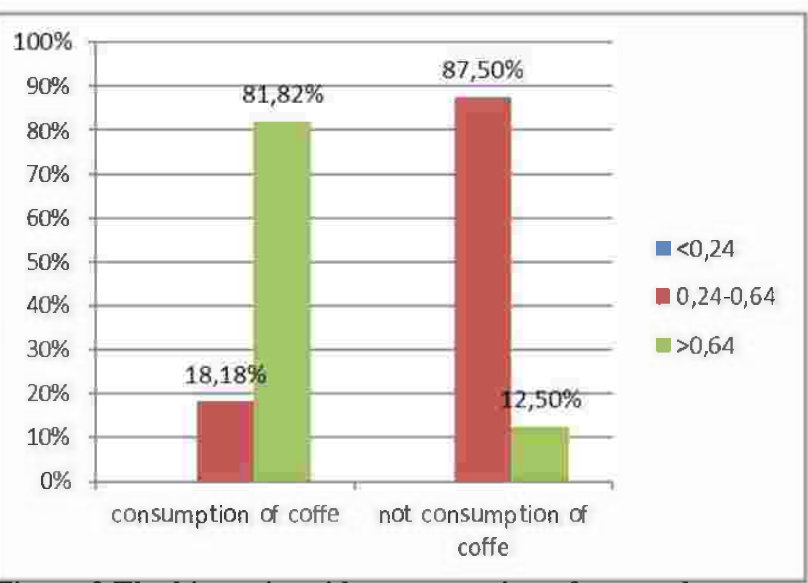

Figure 3 The hippuric acid concentration of respondents with and without coffee consumption in non-fasting condition, Tambak Oso Wilangun Surabaya, 2015.

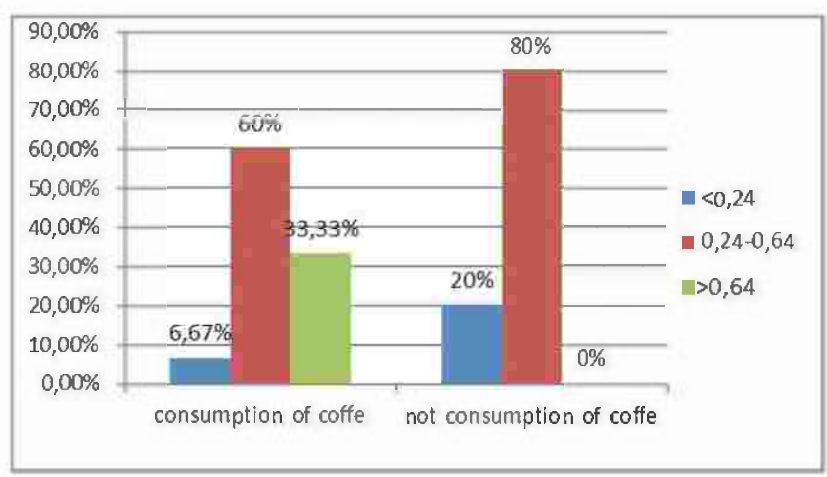

Figure 4 The hippuric acid concentration of respondents with and without coffee consumption in fasting condition, Tambak Oso Wilangun Surabaya, 2015.

Ogawa et. al. in his research report entitled "influence of coffee intake on urinary hippuric acid concentration" revealed that coffee intake increases the urinary hippuric acid. The research was conducted by comparing respondents with toluene exposure and those without toluene exposure. Ogawa et al. added that coffee contains chlorogenic and quinic acids that are metabolised into hippuric acid. In this research, the benzoate acid intake was strictly controlled, so that all hippuric acid excreted were from the coffee intake. It was found out that chlorogenic dan quinic acids were the precursors of hippuric acid ${ }^{11}$.

Other research by Munaka et al entitled "Influence of tea and coffee on biomonitoring of toluene exposure" showed that the frequency of positive hippuric acid concentration ( $>1 \mathrm{gr} / \mathrm{l})$ in heavy consumer of green tea and/coffee was significantly higher than that of nonconsumers (OR 2.34, CI 95\%) $)^{10}$. This research suggested that the research on toluene exposure with hippuric acid as biomarker should involve respondents who are not coffee or green tea consumers to reduce bias. 
In the research conducted in Tambak Oso Wilangun, it was difficult to find respondents who were not smokers and coffee consumers. Therefore, it was assumed that the hippuric acid concentration found at the beginning of the research was contributed by the cigarette and coffee intake. The statistical test showed that there was a correlation between the hippuric acid concentration and coffee intake before and during fasting. When the hippuric acid during the fasting (where the respondents were not smoking and consuming coffee) was tested, it was found that the concentration of hippuric acid $(0.64$ $\mathrm{gr} / \mathrm{L}$ ) was a lot higher. In this case, it could be said that fasting affects the urinary hippuric acid concentration.

Fasting, together with smoking and coffee consumption, increases the urinary hippuric acid concentration. When fasting, the toluene exposure was only from adhesive vapor and its solvent, and it was strongly argued that fasting was the main cause of the increase of hippuric acid concentration. It has been known that fasting can increase the production of cytochrome $\mathrm{P} 450$ which functions as the main route of toluene metabolism into hippuric acid. In this case, fasting benefits the respondents as it increase the urinary hippuric acid excretion.

The increase of hippuric acid in smokers and coffee consumers is caused by the fact that cigarette smoke contains toluene and coffee contains chlorogenic and quinic acid that will be metabolised into hippuric acid. There is an increase of toluene intake among smokers and coffee consumers, and therefore the excretion of hippuric acid increases as well. Both smoking and coffee consumption do not increase the urinary hippuric acid excretion caused by occupational exposure of toluene.

Dr. Anaya Mandal, MD. in his article about caffeine pharmacology proposes that coffee has $5-6$ hour half life $\mathrm{e}^{12}$. When coffee consumption is accompanied with cigarette smoking, then the half life of coffee is half shorter. In other words, coffee contents will have been completely urinary excreted 5-6 hours after the consumption. When the smoking respondents consumed coffee at 4.30 in the morning, they would not longer excrete any hippuric acid metabolite at 10.30 . In this research, hippuric acid sampling was taken from 12.00 to 13.50 in the afternoon, and therefore the urinary hippuric acid excreted was mainly from the occupational toluene metabolite and not from the coffee consumption. More attention should be paid to toluene from cigarette smoke that can be completely excreted after 12 hours 8 . Based on ATSDR report (2007), cigarette smoker absorbs 800-1000 ug toluene per cigarette ${ }^{8 .}$ There was a significant correlation between hippuric acid concentration and smoking in non-fasting condition, but these two were not significantly correlated in fasting condition. In this research, the respondents smoked around $5-16$ cigarettes per day, and the majority of the respondents smoked 12 cigarettes per day. The workers are strongly recommended not to smoke during the work hours, because their bodies have to metabolize not only toluene, but also other dangerous substances taken into the bodies ${ }^{6}$. The excessive amount of toluene that should be metabolized by glycin will reduce its capacity for detoxification of other poisonous substances. This affects the immunity and therefore the workers are vulnerable to health problems.

\section{Conclusion}

This research concluded that the majority of the respondents were exposed to toluene with concentration higher than that of the accepted reference concentration (RfC) value, and therefore they were at risk of health problems. Fasting, coffee consumption, and smoking are factors that can increase the urinary hippuric acid excretion.

\section{Recommendation}

Future research related to toluene exposure may need to control such factors as smoking and coffee consumption to avoid biased results. The respondents are strongly recommended not to smoke when they are at work due to the increase of toluene within the breathing zone and the fact that the toluene vapor is flammable. The respondents are also suggested to wear chemical cartridge respirator, apron, and gloves while working. The installation of electric fans and exhauster is also recommended to improve the ventilation system in the workshops.

Conflict of Interest: All authors have no conflicts of interest to declare.

Source of Funding: This is an article "The Effects of Fasting on Toluene Metabolite (Hippuric Acid) Excretion in Urine (A Case Study of Shoe-makers in Tambak Oso Wilangun Village -Surabaya)"was supported by Faculty of Public Health, Airlangga University, Indonesia, 2017. 
Ethical Clearance: Ethical Clearance took from Faculty of Public Health, Airlangga University, Indonesia Committee

\section{References}

[1] NIOSH $\mathrm{H}^{\mathrm{b}}$, Hippuric Acid in Urine. NIOSH Mamual Analytical Method-Method 8300, Issue 2, dated 15 August 1994 (1994)

[2] Tualeka, Abdul Rohim. Michael Agung Irianto, Adli Prasetyo, Ike Agustin Rachmawati dan Erwin Dyah Nawawinetu. Detoxification of Benzoic Acid in Workers Exposed to Toluene Using Food Rich in Glycine. Indian Journal of Public Health Research and Development. Vol 9, 2018, N o.1, January-March 2018, page 64-69 (2018)

[3] Kolluru, Rao V. Risk Assesment and Management Handbook for Environmental, Health, and safety Professionals. McGraw-Hill. United State of America (1996)

[4] NIOSHa, Toluene. NIOSH Manual Analytical Method-Method 4000, Issue 2, dated 15 August 1994 (1994)

[5] EPA, Toxicological Review of Toluene. CAS No. 108-88-3. In support of Summary Information on Integrated Risk Information System, IRIS. Washington D.C. (2005)

[6] Hogan, C. Michael, "Sulfur", in Jorgensen, A.; Cleveland, C. J., Encyclopedia of Earth, Washington DC: National Council for Science and the Environment, retrieved 26 October
2012, "Sulfur is insoluble in water, but soluble in carbon disulfide, somewhat soluble in other non-polar organic solvents such as the aromatics benzene and toluene." (2011)

[7] ACGIH, TLVs and BEIs, American Vonference of Governmental Industrial Hygienists (ACGIH) 1330 Kempar Meadow Drive, Cicinnati, Ohio 45240. (2010)

[8] ATSDR, "Toluene Toxicity Physiologic Effects", Agency for Toxic Substances and Disease Registry. (2007)

[9] Chalbot, Marie-CecileVei, Ino-Christina Kavouras, Ilias G.Bartziz, Ioannis. Effect of smoking on the levels of urinary biomarkers of aromatic hydrocarbons in oil refinery workers, Stochastic Environmental Research and Risk Assessment. July 2012, Volume 26, Issue 5, pp 731-738 (2010)

[10] Munaka M, Katoh T, Kohshi K, and Sasaki S. "Influence of tea and coffee on biomonitoring of toluene exposure", PubMed (2009) .

[11] Ogawa, M., Suzuku, Y., Endo, Y., Kawamoto, T., Kayama, F.,2011, Influence of Coffee Intake on Urinary Hippuric Acid Concentration, PubMed. gov.US national Library of Medicine, National Institute in health. https://www.ncbi.nlm.nih. gov/pubmed/21173531 (citation, August, 2015)

[12] Mandal, 2014. Caffeine Farmacology, News Medical. AzoNetwork, Copyright 2000 2015. www.news-medical.net/health/caffeine pharmacology.aspx (Citation Jule, 2015) 